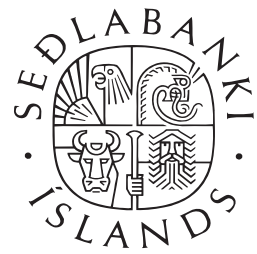

CENTRAL BANK OF ICELAND

WORKING PAPERS No. 20

RENEWABLE RESOURCES IN AN ENDOGENOUSLY

GROWING ECONOMY: BALANCED GROWTH

AND TRANSITIONAL DYNAMICS

by

Lúdvík Elíasson and Stephen J. Turnovsky

November 2002

CENTRAL BANK OF ICELAND

Economics Department 
Central Bank of Iceland Working Papers are published by the Economics Department of the Central Bank of Iceland. The views expressed in them are those of their authors and not necessarily the views of the Central Bank of Iceland.

Also available on the Central Bank of Iceland World Wide Web site (http://www.sedlabanki.is)

All rights reserved. May be reproduced or translated provided the source is stated.

ISSN: $1028-9445$ 


\title{
Renewable Resources in an Endogenously Growing Economy: Balanced Growth and Transitional Dynamics"
}

\author{
Lúdvík Elíasson \\ Central Bank of Iceland \\ and Reykjavík University
}

\author{
Stephen J. Turnovsky \\ University of Washington
}

November 2002

\begin{abstract}
We introduce a renewable resource sector into an endogenous growth model of a small economy, deriving the transitional dynamic equilibrium. The model generates a long-run balanced growth path along which a resource sector of limited size can coexist with constant ongoing growth elsewhere. The key feature of the model is the allocation of labor between harvesting the resource and its use in the final output sector. We examine both the dynamic and long-run responses of the economy to various shocks pertaining to technological production conditions and resource sector parameters and show how they can generate sharply contrasting transitional adjustment paths.
\end{abstract}

Keywords: Endogenous Growth, Renewable Resources, Balanced Growth Path, Macroeconomic Dynamics

JEL Classification: F43, O41, Q22

\footnotetext{
* This paper is based on material in Elíasson's dissertation completed at the University of Washington. We would like to thank Thórarinn G. Pétursson for useful comments. The usual disclaimer applies. The views expressed in this paper do not necessarily reflect those of the Central Bank of Iceland.
} 


\section{Introduction}

Renewable resources are an important component of many small economies. An obvious example is that of Iceland, where in the year 2000 the Fish and Fish Processing sector was around $10 \%$ of GDP, having been $15 \%$ just a decade earlier. The bulk of the fish are sold abroad and the revenues used to purchase imports of consumption and other goods. Another example is New Zealand, which has developed a substantial forestry sector, with much of the timber being harvested for export. More generally, the environment can be viewed as a renewable resource, with pollution generated by economic activity -- i.e. a reduction in the environmental quality -- playing the role of "harvesting" of the resource; see Aghion and Howitt (1998).

The relationship between natural resources and growth is an important issue. Perhaps somewhat surprisingly, empirical evidence suggests that natural resources have an adverse effect on the equilibrium growth rate; see e.g. Gylfason, Herbertsson, and Zoega (1999), Rodriguez and Sachs (1999), Sachs and Warner (2001), and Gylfason and Zoega (2003). Several reasons have been advanced to explain this phenomenon. Sachs and Warner (1995) suggest that a greater abundance of resources may cause economies to shift away from competitive sectors in which externalities necessary for ongoing growth are generated. In contrast, Lane and Tornell (1996) provide a political explanation, arguing that resource booms tend to place resources in the hands of the government, encouraging rent-seeking, rather than growth-enhancing behavior. Rodriguez and Sachs (1999) suggest an alternative hypothesis, namely that resource-rich countries are likely to live beyond their means during a transitional phase while the stock of its resource is being depleted. ${ }^{1}$

In this paper we analyze the equilibrium growth rate for an economy having a renewable resource. In so doing we focus on two main issues. The first is the fact that the harvesting of the resource requires the use of productive factors, such as labor and/or capital, that otherwise could be employed in a final output sector that produces capital goods, thereby enhancing the economy's potential for growth. This provides an alternative explanation for the inverse relationship between

\footnotetext{
${ }^{1}$ Gylfason, Herbertsson, and Zoega (1999) propose another mechanism for the inverse relationship between natural resources and growth, namely that a resource intensive economy is likely to be associated with a more volatile exchange rate, which in turn is likely to inhibit investment and growth.
} 
resource endowment and growth. The second is that by its nature the resource sector is limited in size, which raises questions about the nature of its coexistence with a growing sector in a balanced growth equilibrium. ${ }^{2}$

The literature on renewable resources and growth can usefully be divided into two categories. The first makes assumptions about the resource sector that are necessary for on-going equilibrium growth to persist. Typically it assumes that advances in technology happen sufficiently faster in the use of the resource good than in the use of other inputs, thereby enabling the increasing relative scarcity of the former to be offset. This is done without taking the resource dynamics into account. In addition, the cost of extracting or harvesting the resources is ignored; see e.g. Tahvonen and Kuuluvainen (1991). Also, the resource is often treated as a source of a constant costless exogenous inflow of revenues, very much as in the Dutch disease literature; see e.g. Sachs and Warner (1995). ${ }^{3}$

The second type of growth model with renewable natural resources allows for the resource dynamics, but at the cost of giving up either economic growth or the resource sector in the long run. For example, in the AK model of Stokey (1998) as discussed by Aghion and Howitt (1998, Chapter 5), where the renewable resource serves as a productive input in final output, a positive growth rate of consumption cannot be maintained indefinitely. Herbertsson (1999, chapter 6) introduces a growth model with a resource sector, where its harvest requires the use of capital, thereby recognizing the need to allocate factors of production between the resource sector and other growing sectors in the economy. Capital is allocated between sectors in fixed proportions and he assumes that the resource sector is in equilibrium, which results from free access to the resource. Given these assumptions, he shows that continuous growth is inconsistent with positive equilibrium output in the resource sector: ever accumulating capital would eventually lead to extinction of the resource.

The task of integrating a well-specified model of renewable resources that can maintain a

\footnotetext{
${ }^{2}$ Solow (1999) discusses the use of natural resources in neoclassical growth models. He regards the resource good as one of the inputs used in the production function and concludes that use of renewable resources can be incorporated into the neoclassical growth model without difficulties. The only modification needed is that the exogenous rate of technical change has to be sufficiently fast, such that the effects of increasing relative scarcity of the resource good are offset. However, he suggests that introducing nonrenewable resources in the same way is less satisfactory, because that would rely too heavily on the rate of technical change for the model to remain plausible (Solow (1999, p. 656)).

${ }^{3}$ Rodríguz and Sachs (1999) add a natural resource to a Ramsey growth model. The resource is free in the sense that extraction does not require any resources. Extraction occurs at a decreasing rate, consistent with a fixed rate of harvest in per capita terms (allowing for population growth), or optimal depletion of a (non-renewable) resource.
} 
finite equilibrium size in an endogenously growing economy is an important and challenging endeavor. Several attempts have been undertaken and merit discussion. Aghion and Howitt (1998) derive conditions for ongoing growth where a natural resource is used as an input in the production of a final good. Their result is driven by innovations in the production of intermediate goods. The natural resource in their model is interpreted as environmental quality, but the reader is invited to interpret it as a renewable resource, such as a fishery or a forest. However, while the natural growth function they propose may be appropriate in the context of environmental quality, it is less well suited as a description of traditional renewable resources, such as fisheries or forests. ${ }^{4}$ Bovenberg and Smulders (1996) develop a model in which the equilibrium growth rate is related to the environment, modeled as a renewable resource, through a diverse range of channels. More specifically they write that: “...the natural environment performs several important functions. In particular, environmental quality determines nature's capacity to grow, features an amenity value, and affects the living and working conditions in the economy. Moreover, it absorbs wastes from economic activity and provides natural inputs into production." These far-ranging attributes are also more characteristic of the environment rather than of a more traditional natural resource. ${ }^{5}$

The approach taken in this paper is different from those mentioned above. We focus on a small open economy in which the renewable resource is used to purchase imports of a consumption good, thus characterizing the situation in a number of small economies such as Iceland. A key component of the model is that the harvesting of the renewable resource requires the use of labor, so that an important part of the decision involves the allocation of labor across the resource sector and the final output sector. We show that assuming a conventional Romer-type production function, the equilibrium is such that the traditional sector experiences ongoing growth, while the resource sector maintains a finite size. This of course means that the relative size of the resource sector declines over time, something that is consistent with, for example, the fisheries industry in Iceland.

The main results of our analysis are the following. First, the empirical result that the

\footnotetext{
${ }^{4}$ More specifically, they propose a linear proportional natural growth function, rather than the logistic function, which introduces the carrying capacity of the resource stock, traditionally associated with renewable resources, and specified in equation (2) below. For further discussion of this issue see Eliasson (2001).

${ }^{5} \mathrm{Li}$ and Lofgren (2000) obtain sustainability in a pure consumption growth model with a natural resource by assuming two types of agents, having different discount rates. However, their model abstracts from production.
} 
equilibrium growth rate in an economy endowed with a renewable resource is less than it would be in the absence of such a resource emerges very naturally from our long-run equilibrium. It does so without invoking arguments about over-utilization, rent-seeking, or the sub-optimal allocation of resources. The endowment of a natural resource creates a comparative advantage in the resource good, thus opening up the potential for trade with other countries, and thereby allowing the economy to enjoy more diversity in its consumption pattern than would otherwise be possible. But the cost of this increase in variety is a lower equilibrium growth rate. In addition, we analyze the dynamic and long-run adjustments of the economy in response to a number of changes pertaining to the effects of changes in technology and the structure of the resource sector. Some of these are associated with sharp contrasts between the short-run and long-run effects. To give one example, whereas an increase in the maximum sustainable stock of the resource will be associated with a larger equilibrium stock and a lower long-run growth rate, in the short run the growth rate is likely to be enhanced. This occurs because the long-run accumulation of the resource requires the harvest to be reduced in the short run, diverting productive factors away from the resource sector and toward the internal growth sector, at least during the initial phases of the transition.

The remainder of the paper is structured as follows. The analytical framework is set out in Section 2, with the macroeconomic equilibrium derived in Section 3. Section 4 characterizes the steady state balanced growth equilibrium. The transitional dynamics, particularly in response to the effects of resource sector shocks on the growth path of the economy are discussed in Section 5, while Section 6 concludes.

\section{Analytical Framework}

The economy is endowed with a stock of a renewable resource, $S$, which for expositional purposes we shall identify as being a forest or a fishery. At any point of time, the net rate of change of the resource is given by

$$
\dot{S}=G(S)-X
$$

where $G(S)$ describes the gross reproduction rate of the resource and $X$ is the rate of harvest. The 
reproduction function is assumed to be concave in the current stock of the resource and is typically positive in an interval between $\underline{S}$ and $\bar{S}$ where $\underline{S}$ is the minimum viable stock size, and $\bar{S}$ is the carrying capacity of the environment, the maximum stock of the resource that the environment can sustain, given space and food constraints. ${ }^{6}$ For simplicity, we shall set $\underline{S}=0$ and shall assume that the growth of the resource, $G(S)$, is governed by the logistic function

$$
G(S)=r S(1-S / \bar{S}) \quad r>0
$$

where $r$ is the intrinsic rate of growth of the resource. ${ }^{7}$ In the absence of harvesting, $(X=0)$ and $S$ converges to its maximum sustainable stock $\bar{S}$.

The harvesting of the natural resource requires economic resources and we shall make the assumption $X$ depends only upon labor, in accordance with the production function

$$
X=B L_{X}^{1-\beta} \quad 0<\beta<1
$$

where $L_{X}$ is the amount of labor employed in the resource sector. The constant $B$ may also reflect the possibility that the fishery sector employs a fixed amount of capital. The equation (3) implies that harvest from applying a given effort in the area where the resource is located is independent of the stock size. ${ }^{8}$ This is a plausible assumption for forests where the location of the resource can be easily ascertained. It is also reasonably appropriate for fish that live close to the surface and move around in large shoals, [such as herring, Hannesson 1993, p. 7], in which case the stock keeps its density fairly constant. ${ }^{9}$

The economy comprises a large number of identical infinitely-lived representative agents,

\footnotetext{
${ }^{6} G(S)$ is analogous to a production function, although it differs in that the rate accumulation of the stock is bounded. See Brown (2000) for further discussion of $G(S)$ and its standard properties. Kosela, Ollikainen, and Puhakka (2002) employ a general growth function having the above concavity properties in their analysis of renewable resources in an overlapping generations model. They also discuss the logistic function as a special case.

${ }^{7}$ The logistic function is a standard specification of growth in many fish and animal species; see Brown (2000).

${ }^{8}$ Allowing harvest to share capital with the growth sector introduces complications, since one sector is growing in equilibrium, while the other is limited. It is therefore assumed that the economy is endowed with a fixed amount of labor, which is the only shared input. Similar results would be obtained if sector specific capital is used in addition to labor. See Elíasson (2001, ch. 3) for a growth model in which capital is allocated between a resource sector and a growth sector.

${ }^{9}$ An alternative used specification of the harvest function in the fisheries literature is $X=E S$, where $E$ denotes effort (labor supply); see Brown (2000). The assumption that the harvest is proportional to the abundance of the renewable resource (its stock) may be a reasonable approximation for bottom-dwelling fish, such as cod, see Hannesson (1993). In the Appendix, we summarize the steady-state equilibrium for this alternative formulation.
} 
each of whom produces a domestic final output (nontraded) good using the production function ${ }^{10}$

$$
Y_{i}=A K_{i}^{\alpha}\left(K L_{Y_{i}}\right)^{1-\alpha} \quad 0<\alpha<1
$$

This production function is of the Romer (1986) type and has constant returns to scale in the individual's own capital stock, $K_{i}$, and his labor, $L_{Y_{i}}$, measured in efficiency units, $\left(K L_{Y_{i}}\right)$, where $K$ is the economy-wide average stock of capital and serves as a measure of productivity (knowledge) in the economy. Assuming all agents are identical, $K_{i}=K$, yielding the aggregate production function

$$
Y=A K L_{Y}^{1-\alpha}
$$

where for convenience the subscript identifying the individual can be dropped, and without loss of generality the number of agents can be normalized to unity. Thus the aggregate production function is of the "AK" form, where the productivity of capital is a function of the employment of labor in the final output sector.

The agent is endowed with a unit of labor that can be allocated to harvesting the resource good or producing final output:

$$
1=L_{X}+L_{Y}
$$

The final output that the agent produces can be allocated between consumption, $C_{Y}$, and new capital accumulation,

$$
\dot{K}=Y-C_{Y}
$$

where for simplicity, capital does not depreciate. The agent also consumes an imported consumption good, $C_{Z}$, which is financed by the sale abroad of the (traded) harvested resource, $X$, namely,

$$
p C_{Z}=X
$$

\footnotetext{
${ }^{10}$ While the standard representative agent model is appropriate for our purposes, we should note that an important aspect of the management of renewable resources involves intergenerational allocation issues for which the overlapping generations model is more appropriate. Contributions using the OLG approach include Kemp and Long (1979), Mourmouras (1993), and Koskela, Ollikainen, and Puhakka (2002).
} 
where $p$ is the price of the imported good, in terms of the harvested resource, taken as given.

The representative agent's objective is to choose his consumption, $C_{Y}, C_{Z}$, labor allocation, $L_{X}, L_{Y}$, and his rate of asset accumulation $\dot{K}, \dot{S}$ to maximize the intertemporal utility function

$$
\int_{0}^{\infty} \frac{1}{\gamma}\left(C_{Y} C_{Z}^{\phi}\right)^{\gamma} e^{-\rho t} d t, \quad \gamma<1, \quad \phi>0, \quad \gamma(1+\phi)<1
$$

subject to the resource dynamics (1), the capital accumulation constraint (7), the balanced trade assumption (8) and the allocation of labor (6), given the production functions (3) and (4). The exponent, $\phi$, measures the relative weight assigned to the imported good in utility, and the elasticity, $\gamma$, is related to the intertemporal elasticity of substitution, $s$, by $s=1 /(1-\gamma)$. The utility function is therefore equivalent to the logarithmic utility function if $\gamma=0 .{ }^{11}$ Since the empirical evidence strongly supports $s<1$, we shall maintain the assumption that $\gamma \leq 0$, although it is also convenient to focus on the logarithmic case as a simple benchmark.

Performing the maximization leads to the optimality conditions ${ }^{12}$

$$
\begin{gathered}
C_{Y}^{\gamma-1}\left[p^{-1} B L_{X}^{1-\beta}\right]^{\gamma \phi}=\lambda \\
\frac{1-\alpha}{1-\beta} A K L_{Y}^{-\alpha}=\phi C_{Y} L_{X}^{-1}-\mu B L_{X}^{-\beta} \\
\alpha A L_{Y}^{1-\alpha}=\rho-\frac{\dot{\lambda}}{\lambda} \\
\alpha A L_{Y}^{1-\alpha}-\frac{\dot{\mu}}{\mu}=r(1-2 S / \bar{S}) . \\
\lim _{t \rightarrow \infty} \lambda K e^{-\rho t}=0 \\
\lim _{t \rightarrow \infty} \mu^{\prime} S e^{-\rho t}=0
\end{gathered}
$$

${ }^{11} \ln \left(C_{Y} C_{Z}^{\phi}\right)=\lim _{\gamma \rightarrow 0}\left(\left[\left(C_{Y} C_{Z}^{\phi}\right)^{\gamma}-1\right] / \gamma\right)$.

${ }^{12}$ In performing the optimization the individual agent takes the externality generated by the aggregate stock of capital, $K$, as given. The optimality conditions summarized in (10) evaluate these at equilibrium by imposing the equilibrium condition $K_{i}=K$. Since all agents are assumed to be identical, the subscript $i$ identifying the representative agent is dropped for notational convenience. 
where $\lambda, \mu^{\prime}$ are the shadow values of capital and the renewable resource, measured in terms of the domestic good and the resource good, respectively, and $\mu \equiv \mu^{\prime} / \lambda$ expresses the shadow value of the resource good in terms of the domestic (nontraded) good. The first condition (10a) equates the marginal utility of consumption of the non-traded good to the shadow value of capital where equations (3) and (8) have been used to substitute for consumption of the imported good in the consumption function. Equation (10b) is a key equation and equates the marginal productivity of labor in the two sectors. While the marginal return to employing labor in the final output sector is just its conventional marginal physical product, the marginal benefit yielded by labor in the resource sector equals the marginal utility benefits of the imported consumption good that can be purchased from the harvest less the value of the resources foregone in the process. Equations (10c) and (10d) are two arbitrage conditions. The first of these equates the rate of return to investing in capital, given by the left hand side, to the rate of return on consumption, both returns measured in terms of the domestic final good. The second of these equates the rate of return to investing capital to the rate of return on investing in the resource (fish), given by the right hand side, both returns being measured in terms of the resource good. The last two equations, (10e) and (10f), are transversality conditions asserting that no asset of value should remain at the end of the planning horizon.

\section{Macroeconomic Equilibrium}

The macroeconomic equilibrium we shall consider is one in which in the long-run, domestic final output, its consumption, and capital, all grow at the same balanced growth rate

$$
\frac{\dot{Y}}{Y}=\frac{\dot{C}_{Y}}{C_{Y}}=\frac{\dot{K}}{K} \equiv \tilde{\psi}
$$

while the resource sector (fisheries) is fixed in size. We shall focus our attention on interior solutions, recognizing that polar assumptions on the technology and preferences may lead to the extinction of the resource. The fact that we adopt the logistic growth function helps in the attainment of interior solutions.

We now proceed to use the above optimality conditions to summarize the macroeconomic 
equilibrium in terms of three dynamic equations in the stationary variables, $L_{Y}, c \equiv C_{Y} / K$ and $S$, from which other important variables, in particular various equilibrium growth rates, can be derived. This is accomplished as follows. First, we note the relationship

$$
\frac{\dot{c}}{c}=\frac{\dot{C}_{Y}}{C_{Y}}-\frac{\dot{K}}{K}
$$

and observe that substituting for $Y$ into the capital accumulation constraint (7) and dividing by $K$, we can write

$$
\frac{\dot{K}}{K}=A L_{Y}^{1-\alpha}-c
$$

Next, taking the time derivative of the first order condition (10a) and combining with (10c) yields,

$$
(\gamma-1) \frac{\dot{C}_{Y}}{C_{Y}}+\gamma \phi(1-\beta) \frac{\dot{L}_{X}}{L_{X}}=\rho-A \alpha L_{Y}^{1-\alpha} .
$$

Noting that $\dot{L}_{X}=-\dot{L}_{Y}$ (from (6)) and combining with (11) and (12), equation (13) can be written as

$$
-\frac{(1-\gamma)}{c} \dot{c}-\frac{\gamma \phi(1-\beta)}{L_{X}} \dot{L}_{Y}=\rho+(1-\gamma-\alpha) A L_{Y}^{1-\alpha}-(1-\gamma) c
$$

Now take the time derivative of (10b), which we can express in the form

$$
\frac{\left(\frac{1-\alpha}{1-\beta}\right)\left(A \dot{K} L_{Y}^{-\alpha}-A \alpha K L_{Y}^{-\alpha-1} \dot{L}_{Y}\right)-\phi\left(\frac{\dot{C}_{Y}}{L_{X}}-\frac{C_{Y}}{L_{X}^{2}} \dot{L}_{X}\right)}{\left(\frac{1-\alpha}{1-\beta}\right) A K L_{Y}^{-\alpha}-\phi C_{Y} L_{X}^{-1}}=\frac{\dot{\mu}}{\mu}-\beta \frac{\dot{L}_{X}}{L_{X}}
$$

Combining with (10d), (12) and using $\dot{L}_{X}=-\dot{L}_{Y}$, this can be written as

$$
\begin{aligned}
-\frac{\phi}{L_{X}} \dot{c}-\left[\left(\frac{1-\alpha}{1-\beta}\right)\left[\alpha \frac{L_{X}}{L_{Y}}+\beta\right] A L_{Y}^{-\alpha}+\phi(1-\beta) \frac{c}{L_{X}}\right] \frac{1}{L_{X}} \dot{L}_{Y} \\
=\left[\left(\frac{1-\alpha}{1-\beta}\right) A L_{Y}^{-\alpha}-\phi \frac{c}{L_{X}}\right]\left[(\alpha-1) A L_{Y}^{1-\alpha}-r\left(1-\frac{2 S}{\bar{S}}\right)+c\right]
\end{aligned}
$$

The third dynamic equation is the accumulation equation for the renewable resource 


$$
\dot{S}=r S(1-S / \bar{S})-B L_{X}^{1-\beta}
$$

Thus equations (14a), (14b), and (14c) summarize the macroeconomic equilibrium in terms of three dynamic equations for the variables $\dot{L}_{Y}, \dot{c}, \dot{S}$. The system can be conveniently summarized as

$$
\begin{aligned}
& \left(\begin{array}{c}
\dot{L}_{Y} \\
\dot{c} \\
\dot{S}
\end{array}\right)=M^{-1} N \\
& \text { where }^{13} M \equiv\left\{m_{i j}\right\}=\left(\begin{array}{ccc}
\frac{\gamma \phi(1-\beta)}{L_{X}} & \frac{1-\gamma}{c} & 0 \\
-\left\{\left(\frac{1-\alpha}{1-\beta}\right)\left[\alpha \frac{L_{X}}{L_{Y}}+\beta\right] A L_{Y}^{-\alpha}+\phi(1-\beta) \frac{c}{L_{X}}\right\} \frac{1}{L_{X}} & -\frac{\phi}{L_{X}} & 0 \\
0 & 0 & 1
\end{array}\right) \\
& N \equiv\left\{n_{i}\right\}=\left(\begin{array}{c}
D \\
E F \\
r S(1-S / \bar{S})-B L_{X}^{1-\beta}
\end{array}\right), \text { and } \\
& D \equiv(1-\gamma) c-(1-\gamma-\alpha) A L_{Y}^{1-\alpha}-\rho, \quad E \equiv\left(\frac{1-\alpha}{1-\beta}\right) A L_{Y}^{-\alpha}-\phi \frac{c}{L_{X}}<0, \quad F \equiv(\alpha-1) A L_{Y}^{1-\alpha}-r\left(1-2 \frac{S}{\bar{S}}\right)+c
\end{aligned}
$$

To consider the transitional dynamics, we linearize the dynamic system (15) around its steady state equilibrium, $\tilde{L}_{Y}, \tilde{c}, \tilde{S}$. In performing this, we note that in steady state equilibrium

$$
\tilde{D} \equiv(1-\gamma) \tilde{c}-(1-\gamma-\alpha) A \tilde{L}_{Y}^{1-\alpha}-\rho=0, \quad \tilde{F} \equiv(\alpha-1) A \tilde{L}_{Y}^{1-\alpha}-r\left(1-2 \frac{\tilde{S}}{\bar{S}}\right)+\tilde{c}=0
$$

which together imply

$$
\tilde{S}<\frac{\bar{S}}{2}
$$

so that the steady-state stock of the renewable resource is less than $50 \%$ of its potential maximum, level $\bar{S}$. It is well known that for the logistic growth function, (2), the quantity $\bar{S} / 2$ defines the level of the stock that permits the resource to be harvested at the maximum sustainable rate, referred to in

\footnotetext{
${ }^{13}$ Note that $m_{11}<0, m_{12}>0, m_{21}<0, m_{22}<0, m_{11} m_{22}-m_{12} m_{21}>0$.
} 
the natural resources literature as the maximum sustainable yield (MSY). ${ }^{14}$ The inequality (16a') asserts that the steady-state stock of the resource should be less than the MSY level.

In addition, assuming that the natural resource has positive marginal utility

$$
\tilde{E} \equiv\left(\frac{1-\alpha}{1-\beta}\right) A \tilde{L}_{Y}^{-\alpha}-\phi \frac{\tilde{c}}{\tilde{L}_{X}}<0
$$

Thus, linearizing (15), we have in the neighborhood of steady state

$$
\left(\begin{array}{c}
\dot{L}_{Y} \\
\dot{c} \\
\dot{S}
\end{array}\right)=\left(\begin{array}{ccc}
\omega_{11} & \omega_{12} & \omega_{13} \\
\omega_{21} & \omega_{22} & \omega_{23} \\
\omega_{31} & 0 & \omega_{33}
\end{array}\right)\left(\begin{array}{c}
L_{Y}-\tilde{L}_{Y} \\
c-\tilde{c} \\
S-\tilde{S}
\end{array}\right)
$$

where

$$
\begin{aligned}
& \omega_{11} \equiv \frac{(1-\alpha) A \tilde{L}_{Y}^{-\alpha}}{\Delta}\left[\tilde{E}(1-\alpha) m_{12}-(1-\alpha-\gamma) m_{22}\right]>0 ; \omega_{12} \equiv \frac{1}{\Delta}\left[(1-\gamma) m_{22}-\tilde{E} m_{12}\right]<0 ; \\
& \omega_{13} \equiv-\frac{2 r m_{12} \tilde{E}}{\bar{S} \Delta}>0 ; \omega_{21} \equiv \frac{(1-\alpha) A \tilde{L}_{Y}^{-\alpha}}{\Delta}\left[(1-\alpha-\gamma) m_{21}-\tilde{E}(1-\alpha) m_{11}\right]<0 ; \\
& \omega_{22} \equiv \frac{1}{\Delta}\left[\tilde{E} m_{11}-(1-\gamma) m_{21}\right]>0 ; \omega_{23} \equiv \frac{2 r m_{11} \tilde{E}}{\bar{S} \Delta}>0 ; \omega_{31} \equiv B(1-\beta) \tilde{L}_{X}^{-\beta}>0 ; \omega_{33} \equiv r\left(1-2 \frac{\tilde{S}}{\bar{S}}\right)>0
\end{aligned}
$$

and $\Delta \equiv m_{11} m_{22}-m_{12} m_{21}>0$.

Evaluating the determinant we find that it is

$$
\frac{\tilde{E} r}{\Delta}\left\{A \tilde{L}_{Y}^{-\alpha}(1-\alpha) \alpha \gamma\left(1-\frac{2 \tilde{S}}{\bar{S}}\right)+\frac{2 B}{\bar{S}}(1-\beta)(1-\gamma) L_{X}^{-\beta}\right\}
$$

We will show in the next section that provided a unique feasible solution exists, the term in parentheses is positive, in which case the determinant is negative. It is immediately seen from (17) that the trace is positive, which implies that this system has two positive (unstable) and one negative (stable) eigenvalues. Since the labor allocation and the consumption to capital ratio can adjust instantaneously, while the stock of the resource is constrained to adjust continuously, the equilibrium

\footnotetext{
${ }^{14}$ See Brown (2000) for a discussion of this concept.
} 
in (17) defines a well-behaved saddle path. ${ }^{15}$ Starting from an initial stock of the renewable resource, $S_{0}$, the economy follows the unique stable transitional adjustment path

$$
\begin{aligned}
& S(t)=\tilde{S}+\left(S_{0}-\tilde{S}\right) e^{\eta t} \\
& L_{Y}(t)-\tilde{L}_{Y}=-\left(\frac{\omega_{33}-\eta}{\omega_{31}}\right)(S(t)-\tilde{S}) \\
& c(t)-\tilde{c}=\left[\frac{\omega_{21}\left(\omega_{33}-\eta\right)-\omega_{23} \omega_{31}}{\omega_{31}\left(\omega_{22}-\eta\right)}\right](S(t)-\tilde{S})
\end{aligned}
$$

where $\eta<0$ denotes the stable eigenvalue. The relationships (19b) and (19c) describe the stable saddlepaths for the allocation of labor to the final output sector and the consumption-capital ratio, both of which are negatively sloped. As the equilibrium stock of the renewable resource increases, it is optimal to devote more resources to harvesting, moving labor to that sector and leaving less available for the employment in the final output sector. Intuitively, one can note that the equilibrium is below the maximum sustainable yield (MSY) level. An increase in the stock therefore raises the growth rate of the stock. The harvest rate, and thus employment in the resource sector must rise or otherwise the stock will continue to grow beyond the MSY level. At the same time, the increase in the stock of the renewable resource increases the return to accumulating physical capital, both directly, by raising its relative scarcity, and indirectly by increasing the productivity of labor in the final output sector. Both these effects cause consumption of the domestic (nontraded) good to decline and account for the negative slope of (19c).

Using (19) we can derive linearized stable paths for various growth rates. Recalling (12) and linearizing around the common balanced growth rate, we see that the transitional path for the growth rate of capital is described by

$$
\begin{gathered}
\psi_{K}-\tilde{\psi}=A(1-\alpha) \tilde{L}_{Y}^{-\alpha}\left(L_{Y}-\tilde{L}_{Y}\right)-(c-\tilde{c}) \\
=\left\{-A(1-\alpha) \tilde{L}_{Y}^{-\alpha}\left(\frac{\omega_{33}-\eta}{\omega_{31}}\right)+\left[\frac{\omega_{23} \omega_{31}-\omega_{21}\left(\omega_{33}-\eta\right)}{\omega_{31}\left(\omega_{22}-\eta\right)}\right]\right\}(S(t)-\tilde{S})
\end{gathered}
$$

\footnotetext{
${ }^{15}$ The determinant is certainly negative in the case of the logarithmic utility function $(\gamma=0)$.
} 
which consists of two offsetting effects. The first is due to shifting employment from the resource to the growth sector, (19b). To the extent the current stock of the resource is below its steady-state equilibrium level, employment in the growth sector and the growth rate of capital are both above their respective long-run equilibrium levels. Accordingly, as $S$ increases, during the transition, the growth rate of capital decreases through time. The second is the effect due to the substitution of domestic for imported goods in consumption, (19c). If $S(t)<\tilde{S}, c$ exceeds $\tilde{c}$, causing the growth rate of capital to be below its steady-state level. Thus as $S$ increases through time, this effect declines, thereby raising the growth rate of capital. On balance, the slope of (20) depends upon which effect dominates. The transitional path for the growth rate of output

$$
\frac{\dot{Y}}{Y} \equiv \psi_{Y}=\psi_{K}+(1-\alpha) \frac{\dot{L}_{Y}}{L_{Y}}
$$

and exceeds the growth rate of capital as long as labor is moving to the final output sector.

For expositional simplicity, in describing the transitional dynamics, we shall focus on the case of the logarithmic utility function $(\gamma=0)$, when (20) simplifies to

$$
\psi_{K}(t)-\tilde{\psi}=-A(1-\alpha) \tilde{L}_{Y}^{-\alpha}\left(\frac{\omega_{33}-\eta}{\omega_{31}}\right)\left(\frac{\alpha c-\eta}{c-\eta}\right)(S(t)-\tilde{S})
$$

In this case, the negative labor allocation effect will dominate the positive consumption effect and the $\psi_{K}(t)-S(t)$ locus is unambiguously negatively sloped. Likewise, the corresponding transitional paths for the growth rate of output is:

$$
\psi_{Y}(t)-\tilde{\psi}=-(1-\alpha)\left(\frac{\omega_{33}-\eta}{\omega_{31}}\right)\left[A \tilde{L}_{Y}^{-\alpha}\left(\frac{\alpha c-\eta}{c-\eta}\right)+\frac{\eta}{\tilde{L}_{Y}}\right](S(t)-\tilde{S})
$$

which is also negatively sloped, although less so than (22a). If the intertemporal elasticity of substitution is sufficiently small, the consumption effect in (20) may dominate and the two transitional paths will be positively sloped, with (22b) being steeper. ${ }^{16}$

\footnotetext{
${ }^{16}$ It is also possible for the $\psi_{K}-S$ locus to be negatively sloped but the $\psi_{Y}-S$ locus to be positively sloped.
} 


\section{Steady-State Equilibrium}

Steady-state equilibrium is attained when $\dot{L}_{Y}=\dot{c}=\dot{S}=0$ and is summarized by the following relationships:

$$
\begin{aligned}
& \tilde{c}=\frac{\rho-\gamma \alpha A \tilde{L}_{Y}^{1-\alpha}}{1-\gamma}+(1-\alpha) A \tilde{L}_{Y}^{1-\alpha} \\
& \tilde{\psi}=\frac{\alpha A \tilde{L}_{Y}^{1-\alpha}-\rho}{1-\gamma} \\
& r\left(1-2 \frac{\tilde{S}}{\bar{S}}\right)=\tilde{c}-(1-\alpha) A \tilde{L}_{Y}^{1-\alpha} \\
& r \tilde{S}(1-\tilde{S} / \bar{S})=B\left(1-\tilde{L}_{Y}\right)^{1-\beta}
\end{aligned}
$$

which jointly determine $\tilde{L}_{Y}, \tilde{c}, \tilde{S}$, and $\tilde{\psi}$. Equations (23a) and (23b) are analogous to the corresponding conditions from standard one-sector endogenous growth models with endogenous labor supply; see e.g. Turnovsky (2000). The first term on the right hand side of (23a) describes the conventional dependence of consumption on capital income, and incorporates its income and substitution effects, the net effect of which depend upon the elasticity $\gamma$. The second term reflects the fact that, in addition, consumption increases pari passu with labor income. Equation (23b) asserts that the equilibrium growth rate equals the difference between the return to capital and the rate of time preference, all multiplied by the intertemporal elasticity of substitution, $1 /(1-\gamma)$. Assuming an interior solution in which labor is allocated across the two sectors, $0<\tilde{L}_{Y}<1$, this implies that an economy with a renewable resource sector that requires labor to harvest will in the long-run grow at a slower rate than it would if it were not so endowed.

Equation (23c) combined with (10d) leads to

$$
\frac{\dot{\mu}}{\mu}=A \tilde{L}_{Y}^{\alpha-1}-\tilde{c}=\tilde{\psi}
$$

Thus (23c) describes the equilibrium stock of the renewable resource necessary to ensure that the rate of growth of its shadow value (relative to that of capital) just equals the relative growth rates of 
the two assets themselves, thereby maintaining their relative values along the equilibrium balanced growth path. ${ }^{17}$ Finally, (23d) asserts that in equilibrium the harvest rate must just equal the gross reproductive rate, so that the net stock of the renewable resource remains constant.

Combining (23a) and (23c) implies the relationship

$\mathbf{R R}$

$$
r\left(1-\frac{2 \tilde{S}}{\bar{S}}\right)=\frac{\rho-\alpha \gamma A \tilde{L}_{Y}^{1-\alpha}}{1-\gamma}=\tilde{c}-(1-\alpha) A \tilde{L}_{Y}^{1-\alpha}
$$

Assuming that all wage income is consumed, this equation asserts that in steady-state equilibrium the marginal return to investing in the resource must equal the fraction of income from capital allocated to consumption. In general, it describes a locus between employment in the final goods sector, $\tilde{L}_{Y}$, and the stock of the renewable resource, $\tilde{S}$, that generates the growth rates that will equate the rate of return on the resource to the rate of return on capital, both measured in terms of the domestic good. In the plausible case that the intertemporal elasticity of substitution is less than unity $(\gamma<0)$, this relationship can be easily shown to be negatively sloped and convex with respect to the origin and is illustrated as RR in Fig. 1 and identified as such in (25). ${ }^{18}$

In the case of the logarithmic utility function, the marginal return to the resource must equal the rate of time preference and in this case, the equilibrium ratio of the resource to its potential maximum is simply

$$
\frac{\tilde{S}}{\bar{S}}=\frac{r-\rho}{2 r}
$$

Several interesting observations can be made in this case. First, the long-run equilibrium ratio of the renewable resource to its potential maximum is independent of any characteristics of the harvest function, depending only upon its natural growth rate and the rate of time preference. Also, for

${ }^{17}$ Combining equations (10b) and (23b), we find that the relative value of the natural resource to capital along the equilibrium balanced growth path is

$$
\frac{\tilde{\mu} \tilde{S}}{\tilde{K}}=\frac{\left(\phi \tilde{c} /\left(1-\tilde{L}_{Y}\right)\right)-((1-\alpha) /(1-\beta)) A \tilde{L}_{Y}^{-\alpha}}{r(1-\tilde{S} / \bar{S})}>0
$$

Having determined $\tilde{c}, \tilde{L}_{Y}, \tilde{S}$, the relative value can be readily evaluated.

${ }^{18}$ It is also immediately seen from (25) that $\gamma<0$ is sufficient to ensure $\tilde{S}<\bar{S} / 2$, the MSY level as asserted above. We should point out that it is theoretically possible for $\tilde{S}$ to exceed the MSY level of the resource for implausibly high values of the intertemporal elasticity of substitution $(0<\gamma<1)$. 
plausible values of these two key parameters (e.g. $r=0.05, \rho=0.04$ ) the ratio is extremely low, of the order of $10 \%$. We see further that in this case, the RR locus is a vertical line. Finally, (25) highlights the fact that if the intrinsic growth rate of the resource is less than the rate of time preference, then the equilibrium will be one in which the resource stock is driven to extinction.

Combining (25) with (23b), we may rewrite the former as

$$
r\left(1-\frac{2 \tilde{S}}{\bar{S}}\right)=\rho-\gamma \tilde{\psi}
$$

Written in this way, we can conveniently compare the steady-state stock of capital in this general equilibrium macro growth model with that implied by the standard optimal harvest problem of renewable resources. ${ }^{19}$ Assuming that the objective of the policy maker is to maximize the net value of the harvest, the corresponding optimality condition is (see e.g. Brown 2000):

$$
r\left(1-\frac{2 \hat{S}}{\bar{S}}\right)=\rho
$$

Comparing (26) and (26') we see that in the plausible case where (i) the intertemporal elasticity of substitution is less than one, and (ii) the equilibrium is one of ongoing growth, then $\tilde{S}<\hat{S}$. The two equilibria will coincide if either the utility function is logarithmic (as in $\left(25^{\prime}\right)$ ), or the equilibrium is one of zero growth.

Rewriting (23d) as

$$
\text { HH } \quad r \tilde{S}\left(1-\frac{\tilde{S}}{\bar{S}}\right)=B\left(1-\tilde{L}_{Y}\right)^{1-\beta}
$$

defines a second locus, $\mathrm{HH}$, in Fig 1, which describes the tradeoff between harvesting of the resource and its gross reproduction rate that will maintain a fixed stock of the resource.

Steady-state solutions for $\tilde{L}_{Y}$ and $\tilde{S}$ are defined by the point of intersection of these two curves, assuming that this occurs in the positive orthant. Sufficient conditions for this to be so include

\footnotetext{
${ }^{19}$ See e.g. Conrad and Clark (1987).
} 


$$
\begin{aligned}
& r(1-\gamma)>\rho-\gamma \alpha A \\
& 4 B>r \bar{S}
\end{aligned}
$$

conditions that we shall assume hold. Under these conditions, it is evident from Fig. 1 that the two curves intersect at the unique point A in the positive orthant. Moreover, it is clear that at the point of intersection

$$
\left.\frac{d L_{Y}}{d S}\right|_{R R}<\left.\frac{d L_{Y}}{d S}\right|_{P P}<0
$$

and computing the slopes of the two curves at the intersection point from (24a) and (24b), we can show that at that point

$$
A \tilde{L}_{Y}^{-\alpha}(1-\alpha) \alpha \gamma\left(1-\frac{2 \tilde{S}}{\bar{S}}\right)+\frac{2 B}{\bar{S}}(1-\beta)(1-\gamma) \tilde{L}_{X}^{-\beta}>0
$$

In other words, the condition that there be a unique equilibrium ensures that the determinant of the transitional matrix in (17) be negative, and in conjunction with the trace condition ensures that the dynamic system be a saddle-point is met.

The third locus in Fig. 1, GG, describes the relationship between employment in the final output sector and the equilibrium growth rate specified by (23b). Given the positive but diminishing marginal productivity of labor in that sector, this locus has the concave shape as illustrated.

Table 1 summarizes the equilibrium responses to key parameter changes. An increase in the productivity of the harvest sector, $B$, reduces the equilibrium stock of the renewable resource. Harvesting can be accomplished using less labor, leaving more labor to be employed in the final output (growth) sector, thereby enhancing the growth rate. An increase in the productivity of the final output sector, $A$, will stimulate the employment of labor in that sector, thereby also increasing the growth rate. The reduction of employment in the resource sector, given productivity, will reduce the harvest. With a lower harvest rate the resource stock will be in equilibrium only at a smaller stock size, given that it has to be smaller than the MSY level.

An increase in the maximum sustainable stock of the renewable resource, $\bar{S}$, will have the opposite effects. It will increase the equilibrium stock of the renewable resource, leading to a greater 
proportion of labor being devoted to its harvest, less labor being employed in the final output sector, and a resulting reduction in the equilibrium growth rate. An increase in $r$, the intrinsic growth rate of the renewable resource has precisely the same qualitative effects.

All of these effects can be easily studied in terms of the shifts of the RR and HH curves in Fig.1. We shall use the figure to illustrate two points. First, it illustrates clearly the decline in the long-run growth rate due to the presence of the resource sector. Corresponding to the equilibrium resource stock and labor allocation at point $\mathrm{A}$, we see that the equilibrium growth rate is given by point B on GG. In the absence of a resource sector, all labor would be allocated to final production, $\left(\tilde{L}_{Y}=1\right)$, leading to the higher equilibrium growth rate at the point $\mathrm{C}$.

We can also use the figure to consider the effect of an increase in the rate of time preference; see Fig. 1B. This causes RR to shift to the left causing the equilibrium to move from $\mathrm{A}$ to $\mathrm{C}$ with a reduced stock of the resource and an increase in employment in the final output sector. In addition, the direct effect of the higher $\rho$ is to shift GG to the right. The net effect is that the growth rate shifts from point $\mathrm{B}$ to point $\mathrm{E}$, a move that can be decomposed into two components. On the one hand the direct effect is to reduce the growth rate from $\mathrm{B}$ to $\mathrm{D}$, which is the complete response in a simple one-sector AK model with fixed labor supply. But this is offset by the positive effect stemming from the shift in RR, which is represented by a move along DE.

\subsection{Constant Growth of Resource}

It is of interest to briefly comment on the steady state that would obtain in the case where there is no sustainable maximum stock of the resource so that the growth function describes constant growth, $G(S)=r S$, an assumption that has also been adopted in the literature. ${ }^{20}$ This is obtained by letting $\bar{S} \rightarrow \infty$ in (23), with the RR, and HH locuses now being expressed by

$$
\begin{array}{ll}
\text { RR } & r=\frac{\rho-\alpha \gamma A \tilde{L}_{Y}^{1-\alpha}}{1-\gamma} \\
\text { HH } & r \tilde{S}=B\left(1-\tilde{L}_{Y}\right)^{1-\beta}
\end{array}
$$

\footnotetext{
${ }^{20}$ See e.g. Kemp and Long (1979) and Mourmouras (1993).
} 
In this case the RR locus is a horizontal line that determines equilibrium employment, $\tilde{L}_{Y}$, with $\mathrm{HH}$ then determining the corresponding stock of the resource. In order for (25") to yield an interior solution $0<\tilde{L}_{Y}<1$ the first condition in (28) must be reversed. The GG locus remains unchanged, and determines the corresponding growth rate as before.

If, in addition, the utility function is logarithmic, (25") simplifies further to yield the constraint $r=\rho$, so that the steady-state conditions (23) now provide only three independent relationships to determine the four endogenous variables, $\tilde{L}_{Y}, \tilde{c}, \tilde{S}, \tilde{\psi}$. But in addition, one of the eigenvalues of the linearized dynamic system (17) becomes zero. As a result, the steady state now depends upon the initial stock of the resource, $S_{0}$, and it is the accumulation of the resource from its starting point that provides the additional steady-state relationship.

The structure of the model thus now becomes almost identical to that of a standard small open economy having access to a perfect world capital market. As has been extensively discussed, in such an economy the rate of time preference must equal the world interest rate for an interior steady state to be sustained. This in turn imposes a zero eigenvalue on the dynamics, thereby rendering the steady state dependent upon the initial conditions; see e.g. Turnovsky (1997, Chapter 2). In effect, the constantly growing resource that can be sold on a perfect world commodities market plays the role of a perfectly tradable foreign bond insofar as the small economy is concerned.

\subsection{Centrally Planned Economy}

A well known consequence of the production externality in the basic Romer model being employed here is that it leads to under-investment and a growth rate that is less than would prevail in a first best-best equilibrium. In this economy, the under-investment also has consequences for the resource sector.

It is straightforward to show that a central planner who internalizes the production externality will guide the system to a steady-state equilibrium summarized by:

$$
\text { GG } \quad \tilde{\psi}=\frac{A \tilde{L}_{Y}^{1-\alpha}-\rho}{1-\gamma}
$$




$$
\begin{aligned}
& \text { RR } \quad r\left(1-2 \frac{\tilde{S}}{\bar{S}}\right)=\frac{\rho-\gamma A \tilde{L}_{Y}^{1-\alpha}}{1-\gamma}=\tilde{c} \\
& \text { HH } \quad r \tilde{S}(1-\tilde{S} / \bar{S})=B\left(1-\tilde{L}_{Y}\right)^{1-\beta}
\end{aligned}
$$

By taking account of the social return to investing, the Central Planner shifts the RR curve to the left, (relative to that in a decentralized economy) while the HH curve remains unchanged. This causes labor to be moved from the resource sector to the final output sector, increasing steady-state employment in that sector and leading to a smaller long-run stock of the renewable resource. The

increase in $\tilde{L}_{Y}$ raises the long-run equilibrium growth rate. But in addition, the fact that the central planner is responding to the social return to capital also shifts the GG curve to the left, further increasing the equilibrium growth rate. Thus the decentralized economy grows at a sub-optimally slow rate for two reasons. First, it undervalues the true return to investment, an effect that is present in the one-sector economy. But in a resource-endowed economy this has the further adverse effect of allocating too much labor to the resource sector. As in the one-sector model, this distortion can be fully corrected by subsidizing the return to capital at the rate $s=(1-\alpha) / \alpha .^{21}$

\section{Transition Adjustments}

We now turn to the transitional adjustment of the small open economy, in response to four different types of disturbances. The shocks we consider include: (i) an exogenous price shock, (ii) an adverse shock to the resource, (iii) an increase in technology in the output sector, and (iv) an increase in the sustainable stock of the resource. All of these yield distinct forms of adjustment.

\subsection{Exogenous Price Shock}

The foreign price of the imported good in terms of the resource good (fish), $p$, has been assumed to be an exogenously given constant. This assumption is appropriate, given that the economy is small and it is selling the fish in international markets. The price of fish can thus be interpreted as the terms of trade. We now consider what happens if there is a decline in $p$. Neither

\footnotetext{
${ }^{21}$ See e.g. Turnovsky (2000) for an analysis of optimal tax policy in the one-sector Romer model.
} 
the steady state values of $S, L_{Y}$ and $c$, nor their dynamic equations depend on $p$. If $p$ drops, then the shadow value of capital increases (equation (10a)), and the shadow value of the resource (in units of capital) falls accordingly, offsetting all effects in the dynamic system (equation (15)), which therefore remains unaffected.

There is, however one effect. The reduction in $p$ means that more of the imported good can be acquired in return for fish. A drop in $p$ (an improvement in the terms of trade) results in a higher consumption level at no cost, and therefore unambiguously increases the utility level of the representative agent. This is in contrast to the Brander and Taylor (1997) model, where an increase in the world price could lower the utility level, given that the economy was at an open access equilibrium in autarchy, with the domestic economy consuming the resource good. The model studied here assumes that there would be no use for the resource good in the closed economy. It is simply a currency that is used to pay for imports.

\subsection{Adverse Shock to the Resource Stock}

Assume that the economy is in a steady-state balanced growth equilibrium when the resource stock is hit by an adverse shock. This is represented by a reduction in the initial stock, $S_{0}$ and the dynamics can be conveniently described using Fig. 2. Starting from the steady state at A in Fig 2.A. the shock immediately shifts the economy to a point such as B where the stock size is smaller than in steady state, but the labor allocation has not yet changed. Upon reaching $\mathrm{B}$, labor will be instantaneously reallocated from the resource sector to the growth sector, thus moving from B to X on the stable locus. With the employment in the resource sector reduced, the rate of harvest declines allowing the stock size to recover. As the resource stock accumulates, the share of labor in the resource sector gradually increases. $S$ and $L_{Y}$ move in the direction XA along the stable arm until the initial equilibrium values of $\tilde{S}$ and $\tilde{L}_{Y}$ are restored. While this is happening in the resource sector, the consumption to capital ratio in the growth sector also responds. Following the negative resource shock, the consumption to capital ratio will immediately rise [see (19c)], taking the economy to the stable path in $(c-S)$-space (not illustrated). This happens because as labor shifts from the resource sector, less of the imported good will be available, and the agent compensates by shifting into 
consumption of the non-traded good. Then, as the resource stock recovers, the consumption to capital ratio slowly declines, again until the original equilibrium, $\tilde{c}, \tilde{L}_{Y}$ is regained.

Hence, after the economy completes its recovery to the resource shock, it reverts to the same equilibrium values of the variables $\tilde{c}, \tilde{L}_{Y}$ and $\tilde{S}$ and thus the same equilibrium growth rate $\tilde{\psi}$. However, as is evident from (22a) and (22b), the growth rates of capital and output, $\psi_{K}$ and $\psi_{Y}$ diverge during the transition, before returning to their original common equilibrium value. This is shown in Fig. 2B. For the logarithmic utility function, the initial positive jump in $\psi_{K}$ exceeds that of $\psi_{Y}$ so that immediately after the shock capital grows faster than output. However, as labor moves back to the resource sector during the transition, the growth rate of capital declines more rapidly as both growth rates converge to the common equilibrium growth rate.

This behavior is different from the Dutch-disease models, such as Sachs and Warner (1995), where the resource harvest is treated as an exogenous source of revenues. In those models a shock to the size of the resource is indistinguishable from a price shock, as discussed in Section 5.1.

\subsection{Technological Improvement}

Fig.3 illustrates the dynamics in response to an increase in $A$, the productivity in the final output sector. In the case of the logarithmic utility function there is no long-run effect on either the long-run sectoral labor allocation, $\tilde{L}_{Y}$, or on the stock of the resource, $\tilde{S}$, and hence there are no long-run transitional dynamics. All that happens is that the increase in $A$ raises the productivity of labor employed in the final output sector, leading to an immediate (and sustained) increase in the growth rate. This is illustrated in the Panels A(i) and A(ii) of Fig. 3.

If the intertemporal elasticity is less than unity $(\gamma<0)$, the adjustment takes time. In this case, an increase in $A$ leads to a long-run increase in $\tilde{L}_{Y}$ together with a decline in $\tilde{S}$ (see Table 1). The resource is ultimately going to increase in scarcity, thus raising its shadow value. With forwardlooking agents, the fact that it is known to increase in value will encourage its extraction in anticipation and in the short run labor will switch from final output production to harvesting, causing $L_{Y}(0)$ to decline. The corresponding increase in $L_{X}(0)$ leads to an increase in the rate of harvest and the stock of the resource begins to decline. As this occurs it is optimal to devote less labor to 
harvesting, leaving more available for the employment in the final output sector. Employment therefore undergoes a reversal during the transition.

Panels B(i) and (ii) illustrate the dynamics in the case where $\gamma$ is slightly less than 0 (the intertemporal elasticity of substitution slightly less than one), such that there are transitional dynamics, while at the same time $d \tilde{\psi} /\left.d \tilde{S}\right|_{d A}<d \psi /\left.d S\right|_{\text {stable }}<0$. In this case the direct positive effect of the higher productivity on the growth rate more than offsets the negative effect due to the reduction in $L_{Y}(0)$ and the growth rate of capital initially rises, and continues to rise during the transition, as $L_{Y}(t)$ increases. With labor being attracted to the final output sector, the growth rate of final output exceeds that of capital during the transition. However, as the intertemporal elasticity of substitution declines further, it is possible for the initial negative employment effect to dominate and for the initial growth rates of both capital and output to decline as well, before increasing during the transition. This is illustrated in Panels C(i) and C(ii). ${ }^{22}$

\subsection{Increase in the Sustainable Stock of the Resource}

Fig.4 illustrates the dynamics in response to a technological advance that increases the maximum sustainable stock of the resource, $\bar{S}$. As we have seen this leads to a long-run increase in the steady-state stock of the resource, leading to the long-run reallocation of labor to its harvest, away from the final output sector, causing a decline in the long-run growth rate. The effect on the short-run allocation of labor, and therefore the growth rate, depends upon two offsetting effects. Recalling (19b),

$$
\frac{\partial L_{Y}(0)}{\partial \bar{S}}=\frac{\partial \tilde{L}_{Y}}{\partial \bar{S}}+\left(\frac{\omega_{33}-\eta}{\omega_{31}}\right) \frac{\partial \tilde{S}}{\partial \bar{S}}
$$

we see that on the one hand, the anticipation of the long-run decline in employment in the final output sector tends to have an immediate contractionary effect in that sector. Offsetting that, however, the anticipation of the long-run increase in the resource stock and the corresponding

\footnotetext{
${ }^{22}$ One further case not illustrated arises if the intertemporal elasticity of substitution is sufficiently small for the stable transitional paths of the growth rates to be positively sloped. In this case the growth rates will approach the steady state from above and will therefore initially jump up in response to the shock.
} 
decline in its value will discourage its extraction and in the short run labor will be encouraged to move to the final output sector. In the case of the logarithmic utility function, the net qualitative effect is summarized by

$$
\operatorname{sgn}\left(\frac{\partial L_{Y}(0)}{\partial \bar{S}}\right)=-\operatorname{sgn}\left(\frac{r-\rho}{r}+\eta\right)
$$

For plausible parameters $(r=0.05, \rho=0.04)\left(29^{\prime}\right)$ will be negative as long as $\eta<-0.005$. Given

that $|\eta|$ represents the speed of convergence, the empirical evidence for which exceeds $2-3 \%$ per annum at a minimum, we can be confident that the positive effect dominates in the short run. ${ }^{23}$ Accordingly, in the short run, employment in the final output sector is likely to increase, leading to an initial increase in the short-run growth rate.

Thus we see that both the sectoral allocation of labor and the growth rate will move in the opposite direction in the short-run from how they will ultimately respond. The reason for this is if the equilibrium stock of the renewable resource is to increase in the long run, then during the transition the harvest must initially decline. For this to occur the labor must initially be reallocated from the harvesting of the resource to the production of final output, thereby increasing the growth rate in the short run.

\section{Conclusions}

Renewable resources are important for many small economies. Motivated by this observation, this paper has introduced a renewable resource sector into an endogenous growth model of a small trading economy. We have shown how the macroeconomic equilibrium can be represented by a dynamic system in three stationary variables: the sectoral allocation of labor, the consumption to capital ratio in the growth sector, and the resource stock $S$. We show that for plausible assumptions, the rational agent by taking the shadow value of the resource stock into account, ensures the transitional dynamics are stable. The model thus generates a long-run

\footnotetext{
${ }^{23}$ Empirical estimates of the rate of convergence obtained in empirical growth models range from around $2-3 \%$ to $8 \%$; see Eicher and Turnovsky (1999). These estimates have been obtained for closed economies and are likely to be somewhat faster for small open economies, having access to world financial markets.
} 
equilibrium in which a resource sector of limited size can coexist in an economy that experiences constant ongoing (endogenous) growth in other sectors. This feature, characteristic of some well known situations, such as the Fisheries sector in Iceland, have not always been successfully captured by previous models. In some cases growth is associated with the long-run extinction of the resource sector, while in others, the coexistence may prevail only under restrictive conditions

The steady-state equilibrium is characterized by two features. First, the equilibrium stock of the renewable resource (assuming an equilibrium exists) is smaller than that associated with the maximum sustainable yield. Second, and more importantly, the model very naturally yields the result that the equilibrium growth rate in an economy endowed with a renewable resource is less than it would be in the absence of such a resource.

We have examined both the short-run and long-run responses of the economy to a number of important shocks pertaining to technological production conditions and tastes. We have shown how varying types of shocks can lead to sharply contrasting transitional adjustment paths. In particular, we have contrasted the transitional path for output from capital, showing they diverge in the short run, before ultimately converging to their common equilibrium growth rate.

Of particular interest we find that a larger carrying capacity for the resource (greater resource abundance) implies a larger equilibrium resource stock requiring larger employment in the resource sector for its harvest, leaving less employment in the final output sector and a lower equilibrium growth rate. This is the price paid for the increased variety in consumption made possible by trading the resource good abroad. It provides an additional explanation for the observed long-run negative relationship between resource abundance and growth.

At the same time, by embedding the analysis in a dynamic framework we highlight the intertemporal tradeoffs involved. The accumulation of a larger equilibrium resource stock (in response to greater resource abundance) requires less harvesting in the short run, more employment in the final output sector and therefore a positive short-run relationship between resource abundance and growth. It would be interesting to see the extent to which the empirical evidence is consistent with these theoretical predictions. 


\section{Table 1}

Effects on Long-run Equilibrium

\begin{tabular}{|c|c|c|c|c|}
\hline & B & $\mathrm{A}$ & $\bar{S}$ & $\rho$ \\
\hline$\tilde{S}$ & $\frac{\tilde{L}_{X}^{1-\beta} \tilde{L}_{Y}^{-\alpha} \alpha \gamma(1-\alpha) A}{\Omega}<0$ & $\frac{\tilde{L}_{X}^{-\beta} \tilde{L}_{Y}^{1-\alpha} \alpha \gamma(1-\beta) B}{\Omega}<0$ & $\begin{array}{l}\frac{1}{\Omega}\left\{(1-\gamma) \frac{2 r \tilde{S}}{\bar{S}^{2}} B(1-\beta) \tilde{L}_{X}^{-\beta}\right. \\
\left.-r \frac{\tilde{S}^{2}}{\bar{S}^{2}} \alpha \gamma A(1-\alpha) \tilde{L}_{Y}^{-\alpha}\right\}>0\end{array}$ & $-\frac{B(1-\beta) \tilde{L}_{X}^{-\beta}}{(1-\gamma) \Omega}<0$ \\
\hline$\tilde{L}_{Y}$ & $\frac{\tilde{L}_{X}^{1-\beta}(1-\gamma) 2 r}{\Omega \bar{S}}>0$ & $\frac{-\alpha \gamma \tilde{L}_{Y}^{1-\alpha} r}{\Omega}\left(1-\frac{2 \tilde{S}}{\bar{S}}\right)>0$ & $-\frac{(1-\gamma)}{\Omega} \frac{2 r^{2} \tilde{S}}{\bar{S}^{2}}\left(1-\frac{\tilde{S}}{\bar{S}}\right)<0$ & $\frac{r(1-2 \tilde{S} / \bar{S})}{\Omega}>0$ \\
\hline$\tilde{\psi}$ & $\frac{\tilde{L}_{X}^{1-\beta} \tilde{L}_{Y}^{-\alpha} \alpha(1-\alpha) A 2 r}{\Omega \bar{S}}>0$ & $\frac{\tilde{L}_{X}^{-\beta} \tilde{L}_{Y}^{1-\alpha} \alpha(1-\beta) B 2 r}{\Omega \bar{S}}>0$ & $-\frac{A \alpha(1-\alpha) \tilde{L}_{Y}^{-\alpha}}{\Omega} \frac{2 r^{2} \tilde{S}}{\bar{S}^{2}}\left(1-\frac{\tilde{S}}{\bar{S}}\right)<0$ & $\begin{array}{c}\frac{1}{\Omega}\left\{A \alpha(1-\alpha) \tilde{L}_{Y}^{-\alpha} r\left(1-\frac{2 \tilde{S}}{\bar{S}}\right)\right. \\
\left.-\frac{2 r}{\bar{S}} B(1-\beta) \tilde{L}_{X}^{-\beta}\right\}\end{array}$ \\
\hline$\tilde{c}$ & $\left(\frac{1-\alpha-\gamma}{1-\gamma}\right) A(1-\alpha) \tilde{L}_{Y}^{-\alpha} \frac{\partial \tilde{L}_{Y}}{\partial B}>0$ & $\tilde{L}_{Y}^{1-\alpha}\left[\left(\frac{1-\alpha-\gamma}{1-\gamma}\right)+(1-\alpha) \frac{A \partial \tilde{L}_{Y}}{\tilde{L}_{Y} \partial A}\right]>0$ & $\left(\frac{1-\alpha-\gamma}{1-\gamma}\right) A(1-\alpha) \tilde{L}_{Y}^{-\alpha} \frac{\partial \tilde{L}_{Y}}{\partial \bar{S}}<0$ & $\begin{array}{l}\frac{1}{1-\gamma}\left(1+(1-\alpha-\gamma)(1-\alpha) A \tilde{L}_{Y}^{-\alpha} \frac{\partial \tilde{L}_{Y}}{\partial \rho}\right) \\
\quad>0\end{array}$ \\
\hline
\end{tabular}

$$
\Omega \equiv r\left(\left(1-\frac{2 \tilde{S}}{\bar{S}}\right) \alpha \gamma A(1-\alpha) \tilde{L}_{Y}^{-\alpha}+(1-\gamma) \frac{2 B}{\bar{S}}(1-\beta) \tilde{L}_{X}^{-\beta}\right)>0
$$




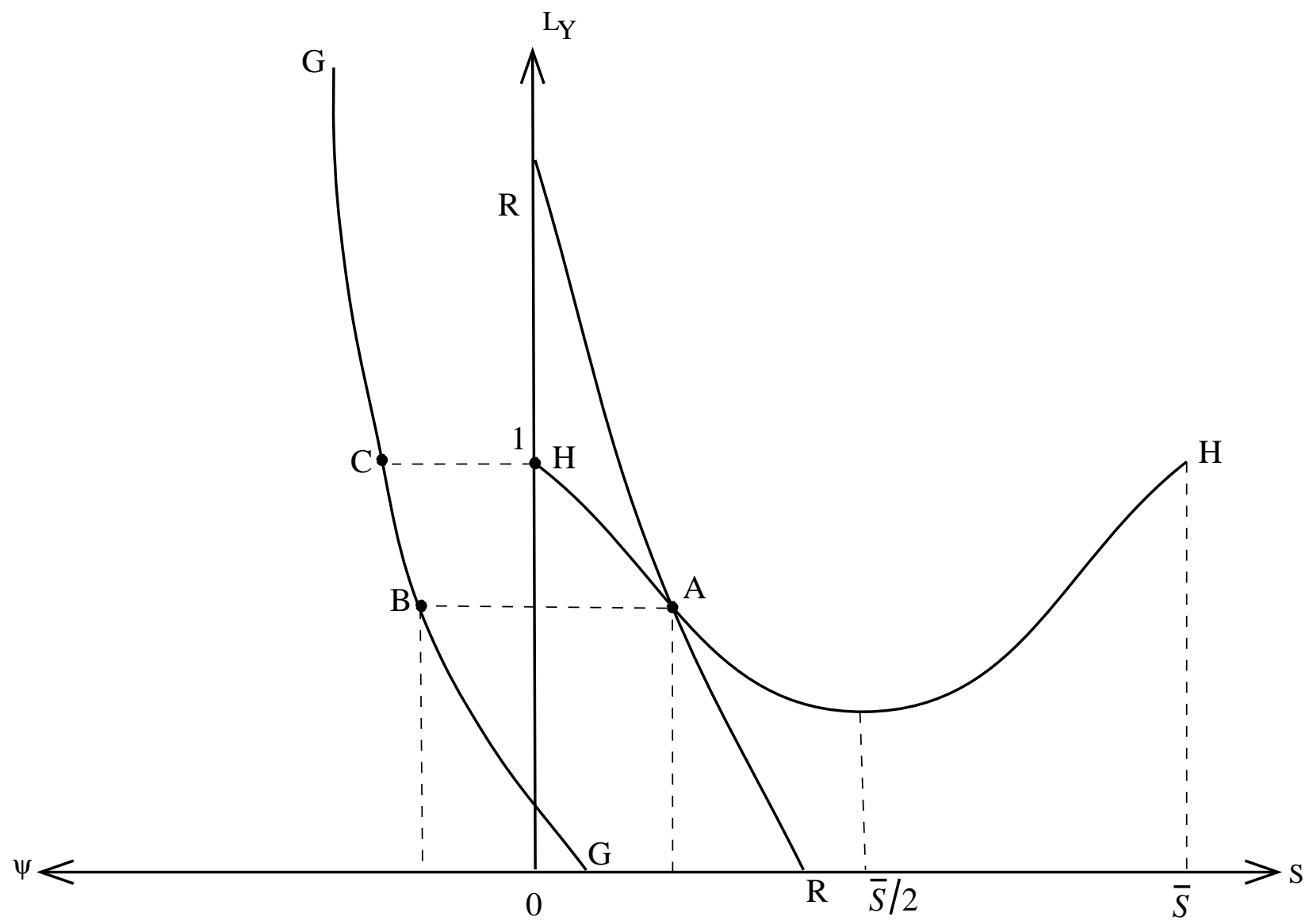

A. Determination of Steady State

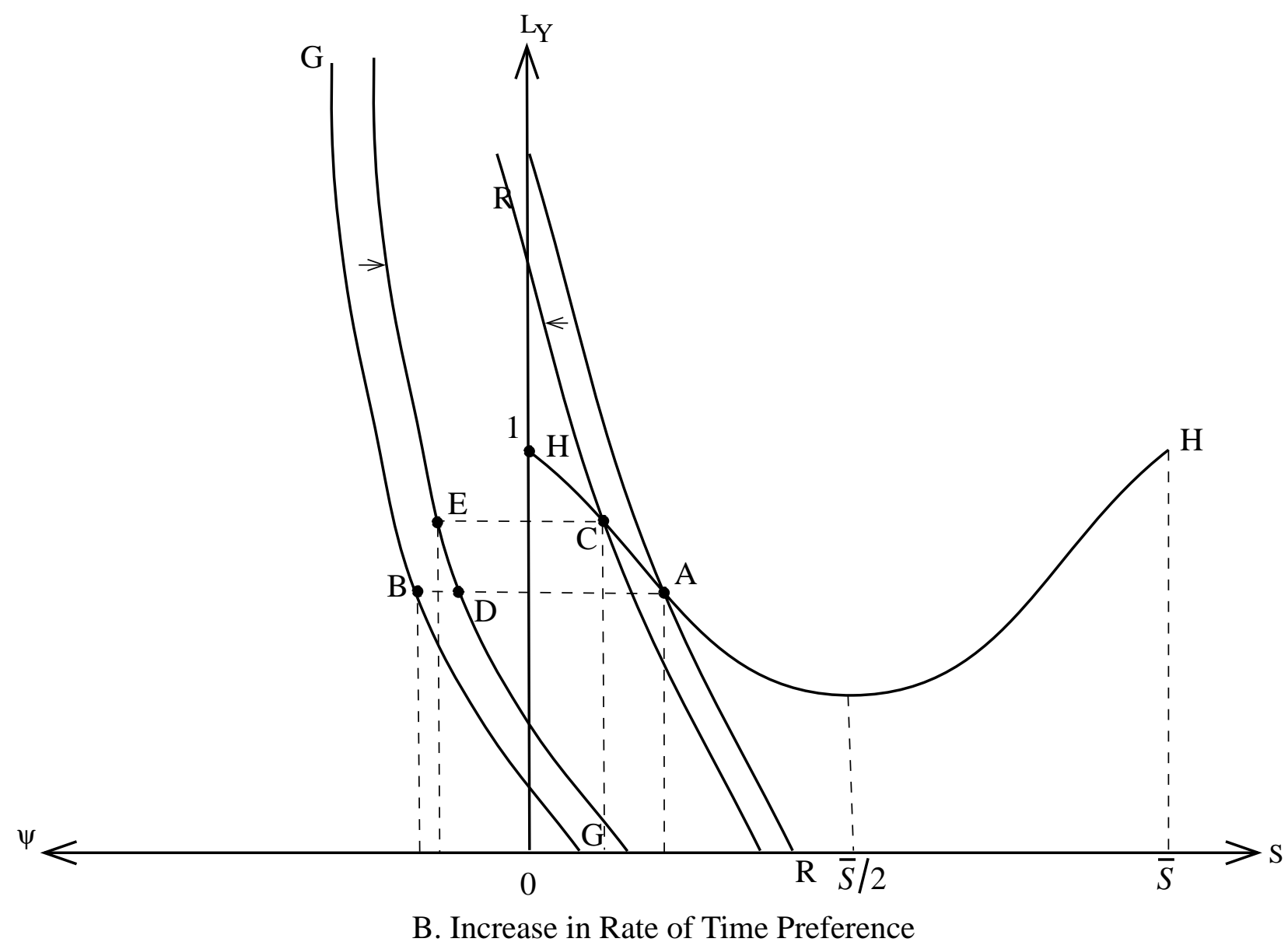

Fig 1: Steady-State Relationships 


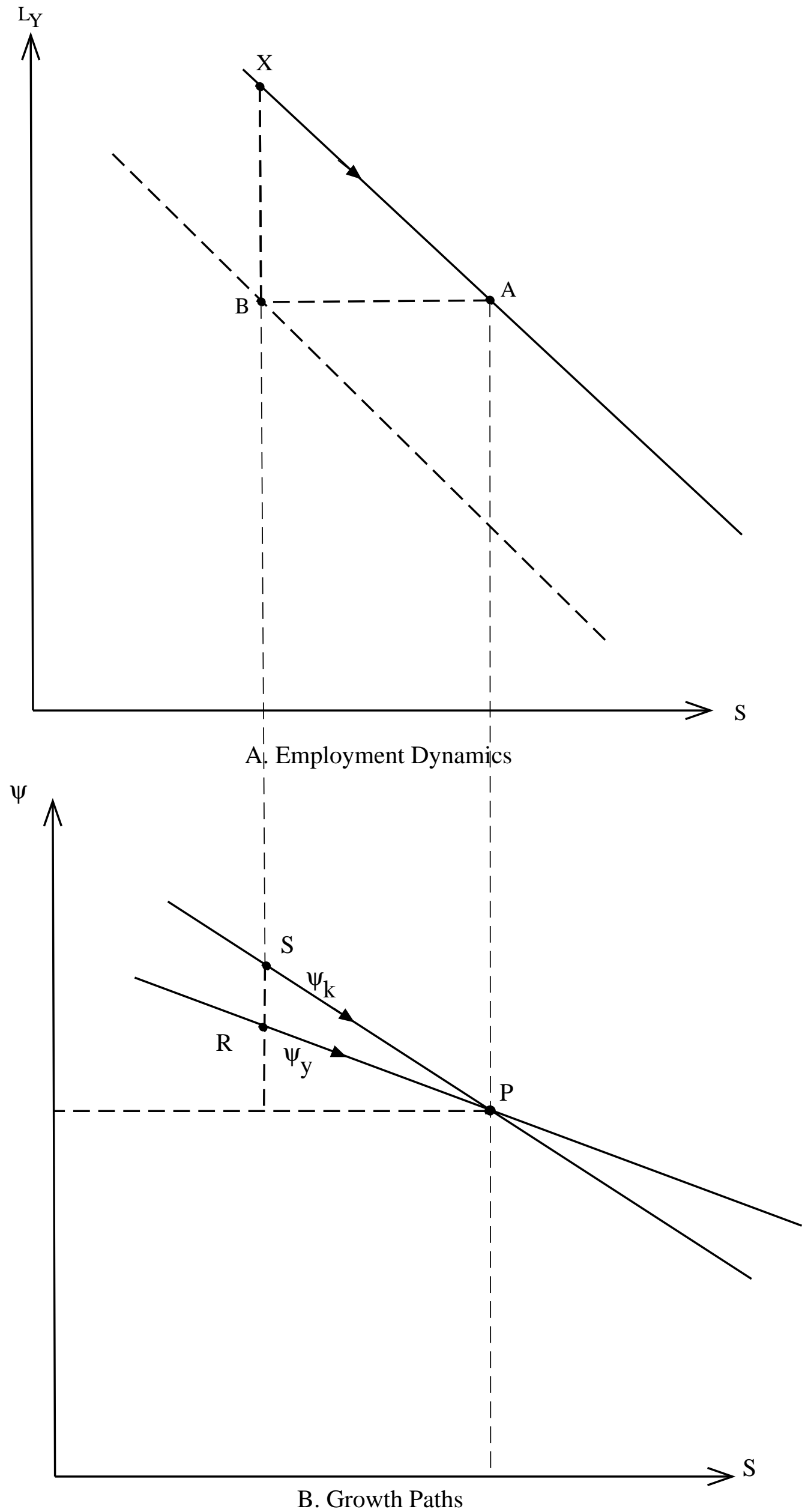

Fig. 2: Adverse Resource Shock 


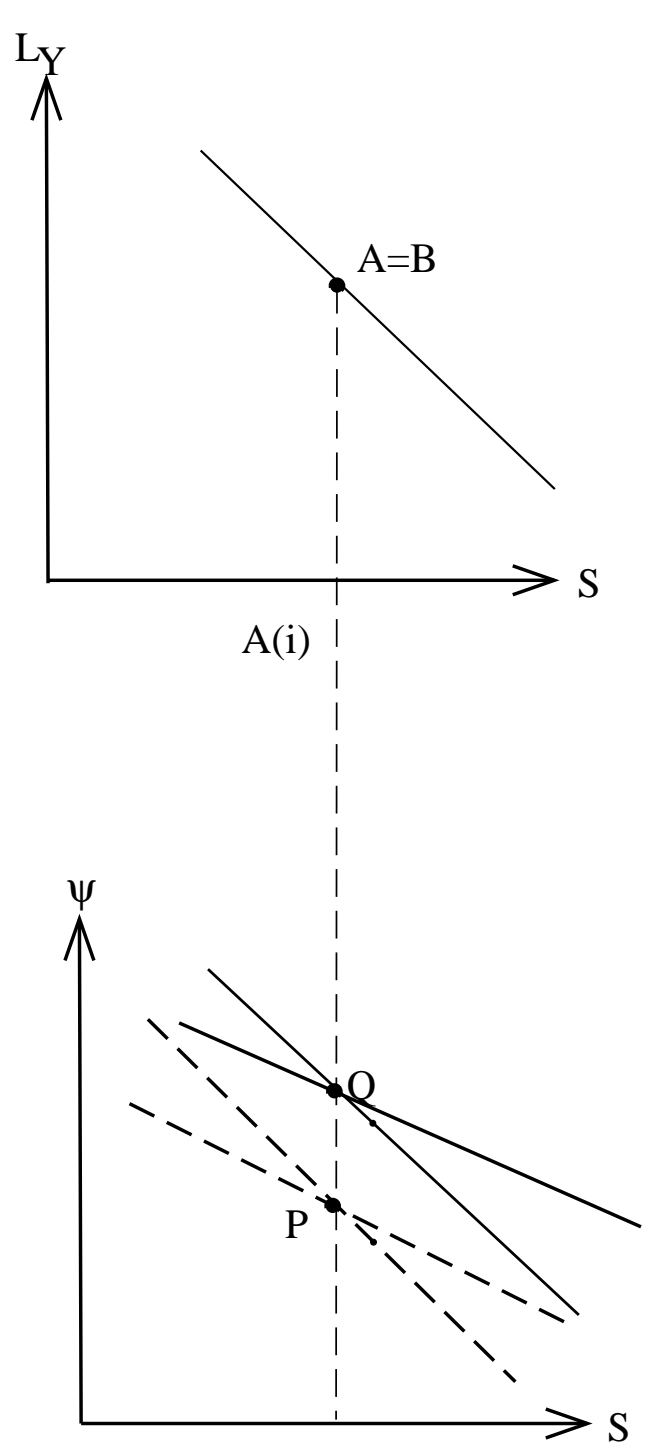

A(ii)
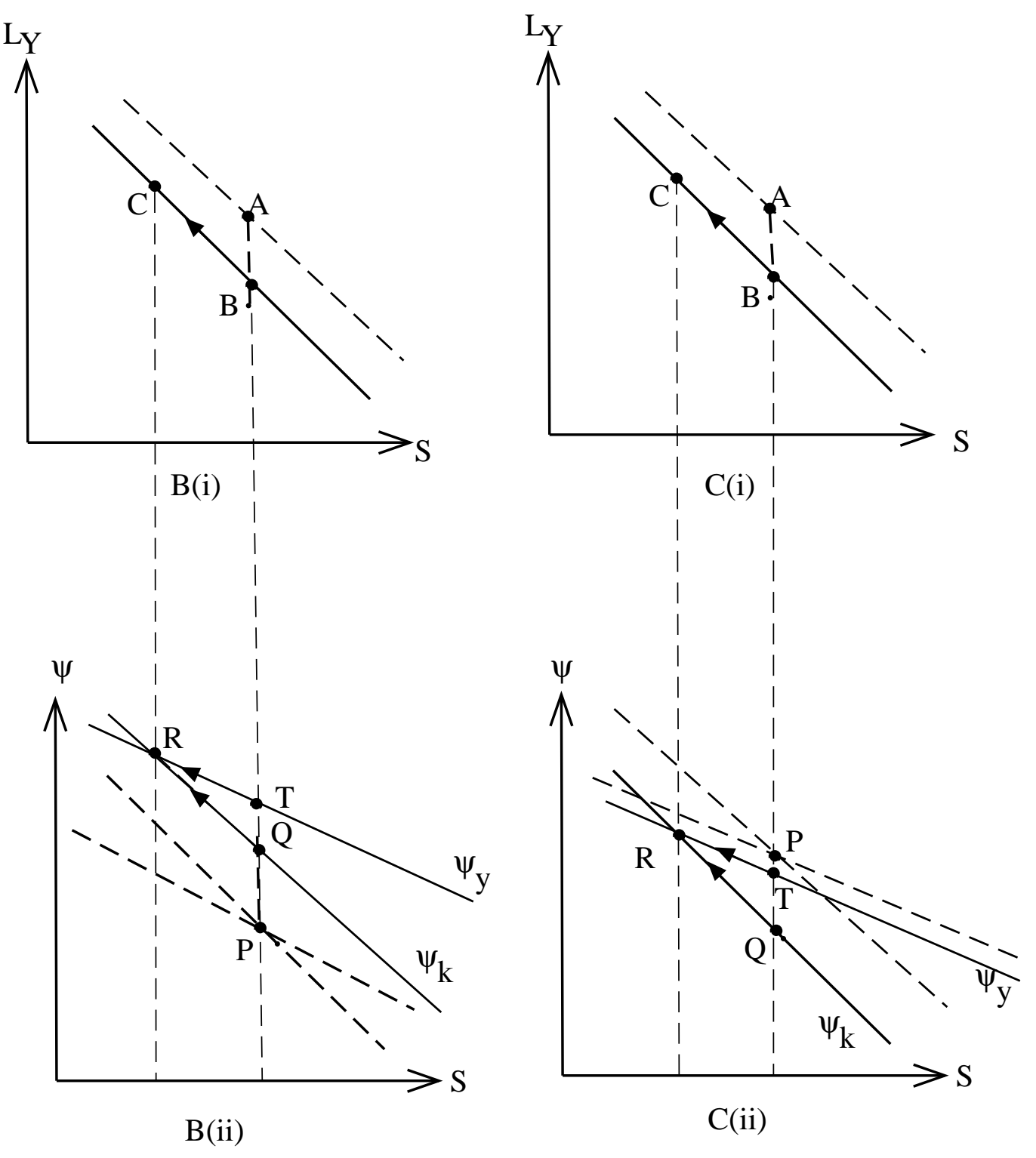

Fig. 3: Increase in Productivity 


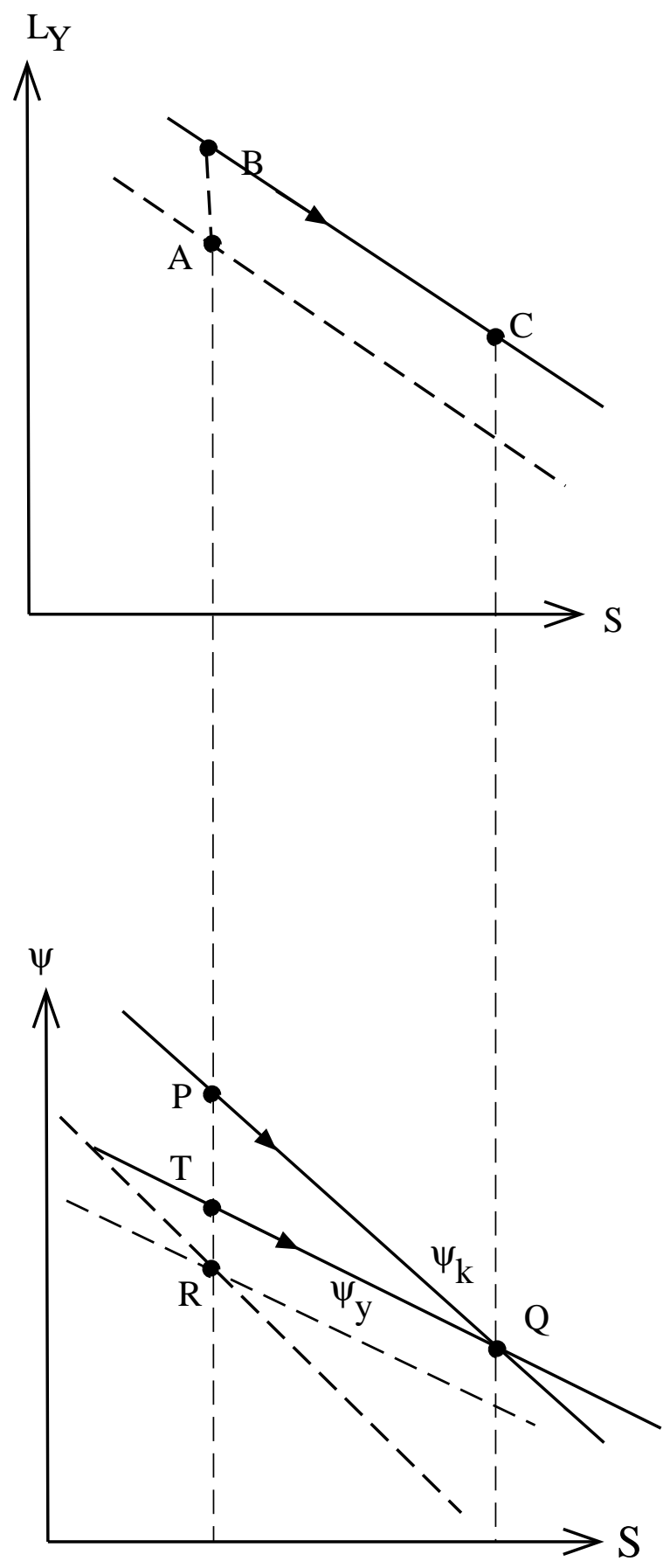

B. Growth Paths

Fig. 4: Increase in Sustainable Stock 


\section{Appendix}

This Appendix sets out the equilibrium in the case that the harvest function (3) is replaced by the alternative specification

$$
X=B L_{X}^{1-\beta} S
$$

so that the harvest cost is proportional to the stock of the resource. The optimality conditions are

$$
\begin{gathered}
C_{Y}^{\gamma-1}\left[p^{-1} B L_{X}^{1-\beta} S\right]^{\gamma \phi}=\lambda \\
\frac{1-\alpha}{1-\beta} A K L_{Y}^{-\alpha}=\phi C_{Y} L_{X}^{-1}-\mu B L_{X}^{-\beta} \\
\alpha A L_{Y}^{1-\alpha}=\rho-\frac{\dot{\lambda}}{\lambda} \\
\alpha A L_{Y}^{1-\alpha}-\frac{\dot{\mu}}{\mu}=r(1-2 S / \bar{S})-B L_{X}^{1-\beta}+\frac{\phi C_{Y}}{\mu S} .
\end{gathered}
$$

together with the accumulation equations

$$
\begin{aligned}
& \frac{\dot{K}}{K}=A L_{Y}^{1-\alpha}-\frac{C_{Y}}{K} \\
& \frac{\dot{S}}{S}=r\left(1-\frac{S}{\bar{S}}\right)-B L_{X}^{1-\beta}
\end{aligned}
$$

and the transversality conditions (10e) and (10f).

The steady-state equilibrium to this system is

$$
\begin{aligned}
& \tilde{c}=\frac{\rho-\gamma \alpha A \tilde{L}_{Y}^{1-\alpha}}{1-\gamma}+(1-\alpha) A \tilde{L}_{Y}^{1-\alpha} \\
& \tilde{\psi}=\frac{\alpha A \tilde{L}_{Y}^{1-\alpha}-\rho}{1-\gamma} \\
& \frac{1-\alpha}{1-\beta} A \tilde{L}_{Y}^{-\alpha}=\frac{\phi \tilde{c}}{\left(1-\tilde{L}_{Y}\right)}-\left(\frac{\tilde{\mu} \tilde{S}}{\tilde{K}}\right) B\left(1-\tilde{L}_{Y}\right)^{-\beta} \\
& r(1-\tilde{S} / \bar{S})=B\left(1-\tilde{L}_{Y}\right)^{1-\beta}
\end{aligned}
$$




$$
A(1-\alpha) \tilde{L}_{Y}^{1-\alpha}-c+\left[r\left(1-\frac{2 \tilde{S}}{\bar{S}}\right)-B\left(1-\tilde{L}_{Y}\right)^{1-\beta}\right]=-\phi \tilde{c}\left(\frac{\tilde{K}}{\tilde{\mu} \tilde{S}}\right)
$$

which jointly determines the equilibrium values of $\tilde{\psi}, \tilde{L}_{Y}, \tilde{S}, \tilde{c},(\tilde{\mu} \tilde{S} / \tilde{K})$. Equation (A.3d) immediately implies $\tilde{S}<\bar{S}$. Eliminating $(\tilde{\mu} \tilde{S} / \tilde{K})$ from (A.3c) and (A.3e), these two equations may be reduced to

$$
r\left(1-\frac{2 \tilde{S}}{\bar{S}}\right)=\frac{\rho-\alpha A \tilde{L}_{Y}^{1-\alpha}}{1-\gamma}-\frac{B\left(1-\tilde{L}_{Y}\right)^{1-\beta} A \tilde{L}_{Y}^{-\alpha}((1-\alpha) /(1-\beta))}{\phi \tilde{c}\left(1-\tilde{L}_{Y}\right)-A \tilde{L}_{Y}^{-\alpha}((1-\alpha) /(1-\beta))}
$$

Written in this way we see that equations (A.3a), (A.3b), (A.3d) are identical to (23a), (23b), (23d), respectively, while (A.3c') is analogous to (23c) (and (25a)). We may also observe the following. First, the fact that (A.3c') is more nonlinear than (25) suggests that the equilibrium is more plagued by non-uniqueness issues than that presented in the text. Second, it is no longer apparent that $\tilde{S}$ is less than the MSY level. This is because the choice of $\tilde{S}$ is now subject to two effects. While the rate of time discount causes the optimal steady-state harvest to be smaller (as in the text), the fact that the harvest increases with the stock has the opposite effect. 


\section{References}

Aghion, P. and P. Howitt, 1998, Endogenous Growth Theory. MIT Press, Cambridge MA.

Bovenberg, A.L. and S. Smulders, 1996, “Transitional Impacts of Environmental Policy in an Endogenous Growth Model," International Economic Review 37, 861-893.

Brander, J.A. and M.S. Taylor, 1997, “International Trade and Open Access Renewable Resources: the Small Open Economy," Canadian Journal of Economics 30, 526-553.

Brown, G.M., 2000, "Renewable Natural Resource Management and Use without Markets,” Journal of Economic Literature 38, 875-914.

Conrad, J.M. and C.W. Clark, 1987, Natural Resource Economics, Cambridge University Press. Cambridge U.K.

Eicher, T.S. and S.J. Turnovsky, 1999, "Convergence in a Two-Sector Non-Scale Growth Model," Journal of Economic Growth 4, 413-428.

Elíasson, L., 2001, Economic Growth with a Renewable Resource Sector, Doctoral dissertation, University of Washington.

Gylfason, T., Herbertsson, T, and G. Zoega, 1999, “A Mixed Blessing: Natural Resources and Economic Growth," Macroeconomic Dynamics 3, 204-225.

Gylfason, T. and G. Zoega, 2003, "Inequality and Economic Growth: Do Natural Resources Matter?" in T.S. Eicher and S.J. Turnovsky (eds.) Inequality and Growth: Theory and Policy Implications, MIT Press, Cambridge MA.

Hannesson, R., 1993, Bioeconomic Analysis of Fisheries, Halsted Press, NY.

Herbertsson, T., 1999, Sources of Economic Growth, University of Iceland Press, Reykjavik, Iceland.

Kemp, M.C. and N.V. Long, 1979, “The Under-expolitation of Natural Resources: A Mopdel with Overlapping Generations," Economic Record 55, 214-221. 
Koskela, E., M.Ollikainen, and M. Puhakka, 2002, "Renewable Resources in an Overlapping Generations Economy without Capital," Journal of Environmental Economics and Management 43, 497-517.

Lane, P.L., and A. Tornell, 1996, "Power, Growth, and the Voracity Effect," Journal of Economic Growth," 1, 213-241.

Li, C-Z., and K-G Lofgren, 2000, "Renewable Resources and Economic Sustainability: A Dynamic Analysis with Heterogeneous Time Preferences," Journal of Environmental Economics and Management 40, 236-250.

Mourmouras, A., 1993, “Conservationist Government Policies and Intergenerational Equity in an Overlapping Generations Model with Renewable Resources," Journal of Public Economics $51,249-268$.

Rodríguez, F.and J.D. Sachs, 1999, "Why do Resource Abundant Economies Grow More Slowly?" Journal of Economic Growth 4, 277-303.

Romer, P.M., 1986, “Increasing Returns and Long-run Growth,” Journal of Political Economy 94, 1002-1037.

Sachs, J.D. and A.M. Warner, 1995, "Natural Resource Abundance and Economic Growth,” NBER Working Paper 5398, Cambridge, MA.

Sachs, J.D. and A.M. Warner, 2001, “The Curse of Natural Resources,” European Economic Review $45,827-838$.

Solow, R.M., 1999, "Neoclassical Growth Theory,” in J. B. Taylor and M. Woodford, Eds., Handbook of Macroeconomics Volume 1A. North-Holland.

Stokey, N.,L., 1998, “Are There Limits to Growth?” International Economic Review 39, 1-31.

Tahvonen, O. and J. Kuuluvainen, 1991, “Optimal Growth with Renewable Resources and Pollution," European Economic Review 35, 650-661.

Turnovsky, S.J., 1997, International Macroeconomic Dynamics, MIT Press, Cambridge MA. 
Turnovsky, S.J., 2000, "Fiscal Policy, Elastic Labor Supply, and Endogenous Growth,” Journal of Monetary Economics 45, 185-210. 